\title{
O verso e o reverso da cooperação federativa e da difusão vertical de políticas para promover capacidade estatal nos municípios brasileiros
}

Grin, Eduardo José

O verso e o reverso da cooperação federativa e da difusão vertical de políticas para promover capacidade estatal nos municípios brasileiros

Administração Pública e Gestão Social, vol. 13, núm. 2, 2021

Universidade Federal de Viçosa, Brasil

Disponible en: http://www.redalyc.org/articulo.oa?id=351566014005

\section{(ㄷ) (1) $\Theta \Theta$}

Esta obra está bajo una Licencia Creative Commons Atribución-NoComercial-SinDerivar 3.0 Internacional. 


\title{
O verso e o reverso da cooperação federativa e da difusão vertical de políticas para promover capacidade estatal nos municípios brasileiros
}

\author{
The verse and the reverse side of federative cooperation and the vertical diffusion of policies to promote state \\ capacity in Brazilian municipalities \\ El verso y el reverso de la cooperación federativa y la difusión vertical de políticas para promover la capacidad estatal \\ en los municipios brasileños.
}

Eduardo José Grin

Fundação Getulio Vargas - São Paulo, Brasil

Redalyc: http://www.redalyc.org/articulo.oa?

eduardo.grin@fgv.br

Recepción: 06 Marzo 2020

Aprobación: 03 Agosto 2020

Publicación: 01 Abril 2021

\section{Resumo:}

Objetivo da pesquisa: Avaliar se a cooperação intergovernamental por meio do Programa Nacional de Apoio à Gestão Administrativa e Fiscal dos Municípios Brasileiros (PNAFM), de 2002 a 2012, desenvolveu capacidades estatais municipais.

Enquadramento teórico: federalismo cooperativo, difusão vertical de políticas e capacidades estatais.

Metodologia: pesquisa quantitativa realizada por meio de painel com efeitos fixos que comparou os municípios em dois períodos: antes do início do PNAFM em 2001 e um ano após o final dos contratos de sua segunda fase em 2012. Foram definidos grupos de tratamento (municípios contratantes) e de controle (que não contrataram) para avaliar o efeito do programa em dois indicadores de capacidade estatal: geração de receita própria e despesas de pessoal.

Resultados: nas duas variáveis de capacidade estatal analisadas o PNAFM não é um modelo adequado de cooperação federativa e de difusão vertical de políticas para promover capacidades estatais municipais. As hipóteses testadas (ampliação da receita própria e redução de despesa de pessoal) são estatisticamente significantes, mas com sinais trocados. Os municípios participantes do programa reduziram sua receita própria e aumentaram a despesa com pessoal.

Originalidade: marco teórico conectando cooperação federativa, capacidades estatais e difusão vertical de políticas. Empiricamente, avalia-se os resultados do PNAFM na promoção de capacidades estatais, considerando que os poucos trabalhos sobre esse programa não adotam esse enfoque. Avaliar a efetividade do PNAFM precisa considerar a literatura de capacidades estatais. A investigação supre uma lacuna ao acrescentar um modelo teórico e um desenho de pesquisa quantitativa que pode servir para novos estudos.

Contribuições teóricas e práticas: A pesquisa contribui com o tema das capacidades estatais municipais: a) teoricamente aborda a questão pelo prisma da difusão vertical de políticas; b) análise econométrica avalia o impacto do PNAFM. Quanto às implicações práticas, a pesquisa sugere que o programa e sua forma de cooperação federativa e de difusão vertical de políticas tende a ser pouco efetiva para as administrações públicas municipais.

Palavras-chave: Receita Municipal Própria, Despesa com Pessoal, PNAFM, Gestão municipal.

\section{Abstract:}

Objective of the research: The objective is to assess whether intergovernmental cooperation through the National Program to Support Administrative and Fiscal Management of Brazilian Municipalities (PNAFM), from 2002 to 2012, developed municipal state capacities.

Theoretical framework: cooperative federalism, vertical diffusion of state policies and capacities.

Methodology: quantitative research carried out by means of a panel with fixed effects that compared municipalities in two periods: before the beginning of the PNAFM in 2001 and one year after the end of the contracts of its second phase in 2012. Treatment groups were defined (contracting municipalities) as well as control groups (not contracting municipalities) to assess the effect of the program on two indicators of state capacity: generation of own source revenue and personnel expenses.

Results: in the two state capacity variables analyzed, the PNAFM is not an adequate model for federative cooperation and vertical dissemination of policies to promote municipal state capacities. The tested hypotheses (expansion of own source revenue and reduction of personnel expenses) are statistically significant, but with inverted signals. The municipalities participating in the program reduced their own source revenue and increased personnel expenses. 
Originality: theoretical framework connecting federative cooperation, state capacities and vertical dissemination of policies. Empirically, the results of PNAFM in promoting state capacities are evaluated, considering that the few extant studies on this program do not adopt this approach. Assessing the effectiveness of PNAFM needs to consider the state capacity literature. Research fills a gap by adding a theoretical model and a quantitative research design that can be used for further studies.

KEYWORDS: Own source revenue, Personnel expenses, PNAFM, Municipal management.

\section{Resumen:}

Objetivo de la investigación: Evaluar si la cooperación intergubernamental a través del Programa Nacional de Apoyo a la Gestión Administrativa y Fiscal de los Municipios Brasileños (PNAFM), de 2002 a 2012, desarrolló las capacidades de los estados municipales.

Marco teórico: federalismo cooperativo, difusión vertical de políticas y capacidades estatales.

Metodología: investigación cuantitativa realizada mediante un panel con efectos fijos que comparó los municipios en dos periodos: antes del inicio del PNAFM en 2001 y un año después de la finalización de los contratos de su segunda fase en 2012 . Se definieron grupos de tratamiento (municipios contratistas) y control (no contratistas) para evaluar el efecto del programa sobre dos indicadores de capacidad estatal: generación de ingresos propios y gastos de personal.

Resultados: en las dos variables de capacidad estatal analizadas, el PNAFM no es un modelo adecuado de cooperación federativa y difusión vertical de políticas para promover las capacidades estatales municipales. Las hipótesis probadas (expansión de ingresos propios y reducción de gastos de personal) son estadísticamente significativas, pero con señales invertidos. Los municipios participantes en el programa redujeron sus propios ingresos y aumentaron los gastos de personal.

Originalidad: marco teórico que vincula la cooperación federativa, las capacidades estatales y la difusión vertical de políticas. Empíricamente, se evalúan los resultados del PNAFM en la promoción de capacidades estatales, considerando que los pocos estudios sobre este programa no adoptan este enfoque. La evaluación de la efectividad del PNAFM debe considerar la literatura sobre capacidad estatal. La investigación llena un vacío al agregar un modelo teórico y un diseño de investigación cuantitativa que se puede utilizar para estudios posteriores.

Aportes teóricos y prácticos: La investigación contribuye al tema de las capacidades estatales municipales: a) aborda teóricamente el tema a través del prisma de la difusión vertical de políticas; b) el análisis econométrico evalúa el impacto del PNAFM. En cuanto a las implicaciones prácticas, la investigación sugiere que el programa y su forma de cooperación federativa y difusión vertical de políticas tienden a ser ineficaz para las administraciones públicas municipales.

Palabras ClaVe: Ingreso municipal propio, Gastos de personal, PNAFM, Gestión municipal.

\section{INTRODUÇÃO}

Após 1988 os municípios brasileiros fortaleceram sua autonomia como ente federativo, ao mesmo tempo em que a descentralização de políticas passou a demandar maior qualidade de gestão. Contudo, o desenvolvimento de capacidades estatais municipais segue sendo um elo pouco considerado na trajetória recente do federalismo brasileiro. Persiste um paradoxo: municípios mais autônomos e tornados peças-chave do Estado de Bem-Estar brasileiro, ao seguirem sendo pouco habilitados administrativa e institucionalmente para implementar políticas públicas, podem enfraquecer o federalismo cooperativo (Grin \&Abrucio, 2018a).

Portanto, a descentralização no Brasil demanda cooperação intergovernamental vertical para induzir ou ajudar a criar capacidades estatais em nível local. Os municípios não podem ser analisados desconsiderando suas conexões com os outros níveis de governo. Nesse contexto, esse artigo avalia o impacto da ação do governo federal para promover capacidades estatais em nível municipal por meio do PNAFM entre 20002 e 2012. Neste período, o programa foi coordenado pelo Ministério da Fazenda (MF) e implementado pela Caixa Econômica Federal (CEF).

As novas atribuições assumidas pelos municípios, após, 1988, ampliaram as exigências para qualificar sua gestão. A literatura que relaciona descentralização de políticas e capacidades administrativas municipais (Abrucio, 2005; Arretche, 1999; Bichir, Júnior e Pereira, 2020; Grin \& Fernandes, 2019; Kugelmas \& Sola, 1999) concorda que existem essas carências no âmbito local. Porém, ainda são poucos os trabalhos que abordam como o federalismo brasileiro se apoia na difusão vertical de políticas para promover a modernização da gestão municipal, para o que esse trabalho espera contribuir teoricamente e empiricamente. 
Por outro lado, a literatura nacional sobre capacidades estatais municipais como fator associado aos resultados obtidos com a descentralização vem sendo adensada nos últimos (Barbosa \& Vaz, 2019; Cardoso \& Marenco, 2019; Fernandes, 2016; Grin \& Abrucio, 2017; 2018a; Grin, Nascimento, Abrucio e Fernandes, 2018; Marenco, 2017; Marenco, Strohschoen \& Joner, 2017; Miranda \& Oliveira, 2018; Vasquez, 2012). Este trabalho segue essa trilha e busca ampliar o conhecimento sobre a gestão municipal ao propor um modelo de análise que identifica variáveis contextuais, governamentais e de difusão vertical de programas federais para avaliar seu efeito sobre as capacidades estatais municipais.

O diálogo com a literatura nacional que discute descentralização, políticas públicas, capacidades estatais municipais e sua conexão com os debates sobre difusão vertical de políticas busca introduzir uma lente teórica para analisar as relações intergovernamentais no Brasil. Assumindo que capacidades estatais são essenciais para os municípios em um contexto de descentralização de políticas que amplia suas responsabilidades, o artigo busca avançar o conhecimento sobre a cooperação federativa voltada à modernização administrativa em nível local. São mais usuais os trabalhos que analisam as relações intergovernamentais em áreas como saúde, educação e assistência. Contudo, como os municípios são o ente federativo que mais responde pela implementação de políticas públicas, é importante analisar as iniciativas federais voltadas a apoiar sua modernização gerencial.

No Brasil, esse é um desafio quando se trata de desenvolver capacidades estatais dos governos locais. O desafio do compartilhamento de responsabilidades se amplia nesse campo de políticas, pois sendo os municípios autônomos em termos administrativos, não é incomum o questionamento sobre a necessidade e a pertinência de ações federais com esse fim. Mas, diante das interdependências intergovernamentais intensificadas com a descentralização de políticas, após 1988, é relevante analisar os tipos de arranjos institucionais e os resultados do federalismo brasileiro para lidar com essa questão de forma coordenada e cooperativa.

A literatura que analisa o PNAFM não é muito extensa no Brasil (Grin, 2014; Grin \& Abrucio, 2017; Pereira, 2018; Reis, Freire \&Wilbert, 2012; Santos \& Pimentel, 2014), de forma que essa pesquisa também visa adensar o conhecimento empírico sobre esse programa do governo federal voltado a promover as capacidades estatais em nível municipal.

Com efeito, fortalecer a capacidade de gestão municipal tornou-se condição imperativa para o federalismo descentralizado no Brasil (Veloso, Monasterio, Vieira e Miranda, 2011). Para abordar esse hiato da cooperação intergovernamental no país, esse trabalho busca responder a seguinte pergunta teórica: programas federais apoiados em autoridades funcionais que formulam e implementam políticas para ampliar as capacidades estatais municipais logram alcançar impactos?

Para realizar essa análise, além dessa introdução, o artigo está organizado como segue. A primeira seção apresenta a origem e as regras do PNAFM relativas à candidatura voluntária dos municípios interessados. A segunda seção apresenta a revisão da literatura, considerando as três dimensões teóricas de interesse: federalismo cooperativo, difusão vertical de políticas e capacidades estatais municipais. Na sequência é apresentada a metodologia quantitativa do trabalho. Considera-se a adesão municipal ao PNAFM como variável independente e despesas com recursos humanos e receitas tributárias próprias como variáveis dependentes para avaliar o impacto na geração de capacidade estatal. O modelo ainda contempla um conjunto de variáveis de controle contextuais e de estrutura governamental. A quinta seção discute os resultados oriundos dos modelos estatísticos que testaram as variáveis de interesse. Na conclusão é cotejada a literatura e o argumento proposto com os resultados da pesquisa.

\section{O PNAFM: HISTÓRICO, ESTRUTURA E REGRAS DE ADESÃO MUNICIPAL}

A partir de 1994, o equilíbrio fiscal tornou-se peça chave da política macroeconômica nacional. Uma das bases desse processo foi a modernização da gestão tributária e financeira dos governos subnacionais (Ministério 
da Fazenda, MF, 2004). Para MF (2008), a política fiscal é condicionada pela organização federativa e a Constituição Federal estabelece competências para cada nível de governo em matéria tributária e de gasto público. Como após 1994 a estabilidade da economia passou a depender do equilíbrio das contas públicas, para alcançar esse resultado, avaliou-se necessário implantar instrumentos de política fiscal também nos municípios. Nessa direção, o PNAFM surgiu com a finalidade de melhorar a administração tributária e financeira municipal (MF, 2007a).

O programa se baseava na adesão voluntária dos entes, desde que respondessem a exigências como: criar uma unidade municipal de execução, alocar recursos no orçamento municipal para pagamento das contrapartidas e do financiamento obtido, atender as regras do crédito público definidas pela Secretaria do Tesouro Nacional e obter autorização legislativa da Câmara de Vereadores para assumir o empréstimo (Cartilha PNAFM, s/d). Para o MF (2004), em face das responsabilidades assumidas pelos municípios com a descentralização encetada após 1988, tornou-se necessário qualificar sua capacidade institucional em face dessa carência para exercerem sua autonomia constitucional. Municípios necessitavam mais eficiência na gestão orçamentária e administrativa, aperfeiçoar o controle fiscal e aumentar a capacidade de arrecadação tributária. Centralmente, o PNAFM foi instituído para melhorar a eficiência administrativa e fortalecer a gestão de recursos humanos (Cartilha PNAFM, s/d; MF, 2006).

Nesse contexto, a União solicitou apoio ao Banco Interamericano de Desenvolvimento (BID) para promover a modernização da gestão administrativa e fiscal municipal, visando gerar equilíbrio fiscal autosustentável em suas três esferas de poder. As negociações tiveram início em 1998 e no ano seguinte realizou-se um diagnóstico da gestão fiscal em 50 municípios. O estudo realizado pelo BID e MF embasou a formulação do programa ao identificar deficiências no manejo da receita e do gasto público, baixos níveis de arrecadação própria, ausência de códigos tributários, cadastros desatualizados de contribuintes e baixa capacidade para elaborar orçamentos e controles na administração financeira (MF, 2004).

Em 1999, o Senado Federal autorizou a operação de crédito junto ao BID para financiar o PNAFM, em sequência à aprovação do Regulamento Operativo do Programa. Em 2000, com a aprovação da Lei de Responsabilidade Fiscal (LRF), postergou-se a formalização do programa (MF, 2006). Em maio de 2001 foi contraído o empréstimo do governo brasileiro junto ao BID e o Senado Federal aprovou a Resolução n. 43/2001 que dispõe sobre concessão de crédito no setor público e define restrições para contratação de dívidas subnacionais (MF, 2007b; 2008). O Senado regulamentou as operações de crédito do programa que, dessa forma, pode iniciar suas atividades em maio de 2002.

Sua implementação visava fortalecer o pacto federativo constitucional ao estimular a modernização da gestão administrativa e fiscal dos municípios (MF, 2005, p. 4). O PNAFM visava desenvolver capacidades de governança em um contexto de descentralização. Contudo, em nível local, o incremento em receitas próprias de $196 \%$, entre 1988 e 2000, indicava que havia um potencial tributário não explorado (Afonso \& Araújo, 2000). Para tanto, era necessário investir na modernização da gestão fiscal e administrativa municipal para que ampliassem sua autonomia no financiamento do gasto público, desempenhassem melhor suas funções e cumprissem regras da LRF.

O PNAFM visava recuperar a capacidade de investimento e a autonomia financeira local que, em última análise, contribuiria para fortalecer a própria Federação (MF, 2007a). Avaliava-se que, contrariamente à tese da "preguiça fiscal", os municípios podiam ser estimulados a ampliar suas receitas próprias. $\mathrm{O}$ efeito seria aumentar sua capacidade de implantar uma administração financeiramente sustentável e com melhor qualidade dos serviços públicos.

Em função da diversidade dos níveis de capacidade gerencial e variação da demanda de serviços definiramse dois tipos de projetos - simplificado e ampliado - , subdivididos em 18 grupos populacionais. As faixas 1 a 5: cidades com até 50 mil habitantes só contratavam a versão simplificada. As faixas 10 a 18: localidades com mais de 150 mil habitantes só podiam acessar a modalidade ampliada. As faixas 6 a 9 - população entre 50.000 e 150.000 habitantes - podiam implementar um ou outro, conforme suas necessidades, mas 
mediante aprovação do MF. Justificou-se esse desenho baseado no porte populacional, localização e nível de desenvolvimento local para assegurar uma distribuição equitativa entre os diversos tamanhos e tipos de municípios $^{[2]}$.

Para responder aos objetivos do programa sua estrutura de coordenação federativa é a que segue na figura 1.

\section{ESTRUTURA DO PNAFM}

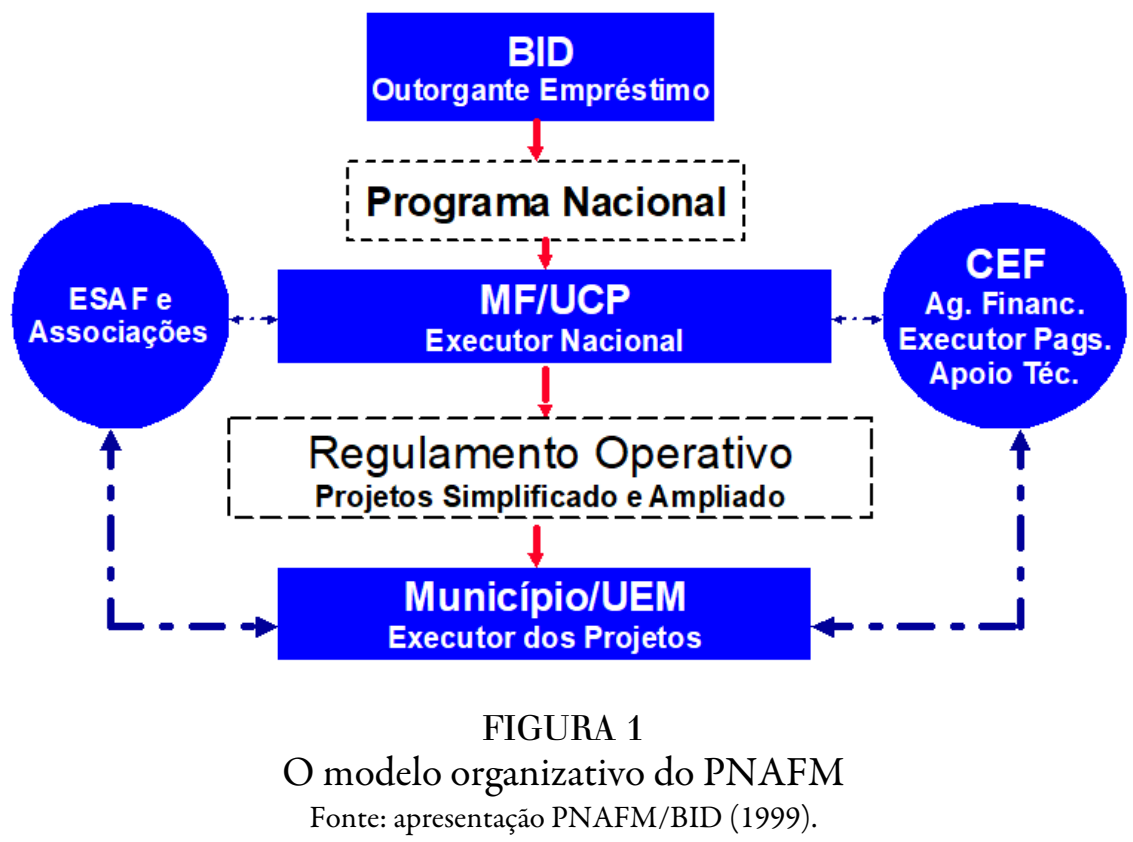

A Unidade de Coordenação de Programas (UCP) da Secretaria Executiva/Diretoria de Gestão Estratégica do MF era o órgão executor e a CEF o agente financeiro e co-executor. Os municípios, ao assinarem o termo de adesão, deviam formalizar a Unidade Executora Municipal (UEM). Estas elaboravam os projetos, coordenavam e supervisionavam a execução e administravam a aplicação dos recursos financeiros. Agências implementadoras, como a Escola Superior de Administração Fazendária, apoiavam a capacitação dos servidores municipais. Os municípios eram os submuturários e executores por meio das Secretarias municipais, especialmente nas áreas de Finanças, Planejamento e Administração. Concluídas as contratações das duas primeiras fases até o final de 2014, houve 106 projetos referentes a 101 cidades (78 ampliados e 23 simplificados, considerando que algumas contrataram pelo menos duas vezes) ${ }^{[3]}$, o que representou $1,81 \%$ dos 5570 municípios.

Dos vários objetivos que o PNAFM possuía, nessa pesquisa, avalia-se o impacto de dois: a) melhorar a administração tributária e financeira municipal; b) melhorar a eficiência administrativa e fortalecer de recursos humanos. Como assinalado acima, ambos representam finalidades estratégicas buscadas pelo programa para modernizar a gestão municipal.

\section{Federalismo cooperativo, difusão vertical de políticas e CAPACIDAde estatal}

O federalismo cooperativo é uma construção política sobre relações entre esferas de governo. Todavia, os entes federativos podem aderir às iniciativas intergovernamentais ou optar por manter sua autonomia. Portanto, a cooperação federativa é um processo contínuo que visa gerar consensos equilibrados entre políticas emanadas da esfera central com a manutenção da autonomia subnacional. E assim é pois o pacto 
federativo (Elazar, 1987) não se constitui pela imposição das prioridades oriundas do governo central (LaeCho \& W right, 2001), mas sim por mecanismos de indução que sejam considerados benéficos pelos governos locais. Iniciativas federais voltadas a promover as capacidades estatais dos entes subnacionais se inserem nessa concepção e desenho das relações intergovernamentais (Kim, McDonald \& Lee, 2018).

A organização desses vínculos podem ser de três tipos, conforme os autores e tradições teóricas destacadas por Agranoff (2001): a) Anderson (1960) (cooperação territorial entre todos os níveis de governo por meio de seus officials); b) Grodzins (1984) (policy oriented ao enfocar como agências públicas e seus gestores em distintos governos colaboram mutuamente); e c) Elazar (1962) ("hard cases" de programas como estudos de caso4). A terceira vertente teórica será a base para a discussão do PNAFM.

Programas federais permitem avaliar como opera a "acomodação mútua" de agendas e os graus de cooperação como seu modus operandi (Agranoff, 2001). Mais especificamente, "os mais frutíferos estudos de capacidades estatais tendem a focar-se sobre arenas particulares de políticas" (Skocpol, 2002, p. 17). Uma das formas de organização federativa reside na implementação de arranjos intergovernamentais oriundos de burocracias constituídas como autoridades funcionais. A atuação dessas estruturas costuma basear-se em regras próprias, o que pode afetar a performance dos programas que são ofertados em nível nacional (Biesbroek, Peters \& Tosun, 2018; Peters, 2015). Este tipo de organização configura o que Wright (1988) chama de subgovernments: burocracias que assumem relevância como proponentes de política que acabam por moldar a cooperação intergovernamental. Combinam razoável autonomia funcional com grande capacidade de enforcement na implementação de regras de acesso por esferas subnacionais de governo. Discricionariedade, insulamento, baixa inclusão de atores federativos e seu locus institucional são características chave (Grin \& Abrucio, 2019; Wright \& Stenberg, 2006) em se tratando de programas federais de assistência direta (Collins, Andrew \& Khunwishit, 2015).

A existência de órgãos especializados na administração federal, mas com capacidade de produzir decisões que geram efeitos sobre outras esferas de governo, pode gerar um paradoxo na cooperação federativa. Ainda que as finalidades sejam meritórias, como é o caso de promover capacidades estatais municipais, os resultados podem ser pouco alentadores. A noção de estilos de políticas ajuda a explicar as preferências dos subgovernments por diferentes instrumentos para lidar com certas policy issues. As opções afetam a estrutura interna do mix de objetivos, regras, instrumentos e também os alvos das políticas e programas. Ainda que os resultados possam ficar aquém do previsto, policy officials geralmente trabalham alinhados com um conjunto pré-estabelecido de objetivos de políticas e preferências sobre suas formas de implantação (Howlett, 2009; Howlett \& Tosun, 2019; Stead, 2018).

Uma das maneiras de organizar um estilo de política marcado pela prevalência dos subgovernments é a difusão vertical de políticas ou programas. Esse processo ocorre quando as opções e ações de um nível de governo influenciam as políticas e comportamentos de outras esferas (Kim, McDonald \& Lee, 2018), ainda que a escolha possa ser por não adotar esses instrumentos. A obtenção da adesão subnacional para uma política federal pode incluir diversos mecanismos, que podem variar da coerção até candidaturas voluntárias baseadas na discrionariedade local (McDonald \& Gabrini, 2014).

Um dos fatores que conduzem a difusão vertical de políticas em países federais é a construção de capacidade estatal de governos locais (Kim, McDonald \& Lee, 2018). Ainda que capacidade estatal seja um conceito polissêmico, a literatura compreende que engloba algumas dimensões chave, como é o caso da gestão fiscal e recursos financeiros próprios (Luna e Soifer, 2017; Wolman, McManmon, Bell, \& Brunori, 2010), recursos humanos (Evans, 2003; Grindle, 1997; Olsen, 2005) infraestrutura organizacional e habilidades técnicas (Pierson, 1995, Skocpol, 2002) e controle de suas próprias operações (Burgess, 1975; McDonald \& Gabrini, 2014) Estas são chamadas de "capacidades centrais", pois a disponibilidade de recursos financeiros e staffs qualificados tecnicamente são fatores críticos para a gestão governamental e sua eficácia decisória (Bowman \& Kearney, 1988). 
Como a construção dessas capacidades é um "elemento chave" nas relações intergovernamentais, importa clarificar o status e as demandas da assistência técnica federal para alcançar esse resultado juntos aos governos locais (Burgess, 1975; Kim et al., 2018). Este processo de difusão vertical pode apoiar os municípios no fortalecimento de sua infraestrutura institucional para implantar políticas (Schmitter, Wageman, \& Obydenkova, 2005; Sikkink,1991). Nessa linha, investigar capacidades estatais consiste em identificar estruturas organizacionais cuja ausência ou presença sejam críticas para a ação governamental (Rueschemeyer \& Evans, 2002).

Portanto, construir e qualificar o aparato burocrático deveriam ser as primeiras tarefas, visando fortalecer as habilidades do Estado e suas condições para implementar políticas (Evans, 1995; Grindle, 1996; Olsen, 2005). Conforme Evans (2003), a existência de burocracias organizadas é um bem escasso, o que remete ao tema dos incentivos à sua institucionalização. Geddes (1994) enfatiza que preferências de políticas dos governos precisam desenvolver condições de implementação, para o que qualificar suas capacidades estatais é uma condição necessária.

O desenvolvimento de capacidades estatais não pode ser explicado por um único fator, mas a indução federativa se configura como uma dessas rotas para incentivar os entes subnacionais a modernizarem sua gestão. Em linha com Glenday (1997), esse caminho metodológico será utilizado para avaliar se o PNAFM, com seus mecanismos de indução federativa, foi capaz de promover capacidades estatais nos municípios que voluntariamente aderiram ao programa. Considerando a pergunta teórica, o argumento desse trabalho é que programas como o PNAFM, formulados e implementados pelas burocracias especializadas do MF e da CEF, não são capazes de obter resultados na modernização das capacidades estatais municipais.

\section{Metodologia da pesquisa}

Essa pesquisa analisa empiricamente um programa federal e se baseia em uma pergunta teórica, visando gerar inferências generalizáveis para formatos similares de cooperação intergovernamental voltados a promover capacidades estatais municipais. Quanto aos seus instrumentos de análise, este é um estudo quantitativo que avalia o impacto do PNAFM na promoção de capacidades estatais municipais. Para tanto, duas são as variáveis dependentes selecionadas: a) esforço de arrecadação local: razão entre receita municipal própria ${ }^{[6]}$ e a receita corrente realizada; b) despesa de pessoal é a razão entre despesas com pessoal ativo e as despesas correntes ${ }^{[7]}$.

Estas duas variáveis dialogam com a literatura e são teoricamente válidas para avaliar o impacto produzido pelo programa em dois de seus objetivos centrais. Capacidades estatais são multidimensionais (Cingolani, 2013) e podem ser mensuradas por meio de muitos indicadores. Nesta pesquisa, para avaliar o impacto do programa, foram selecionadas duas variáveis alinhadas a dois de seus objetivos-chave: ampliar receita própria e reduzir despesa de pessoal. Assim, não se reduz o tema das capacidades estatais a essas duas variáveis, mas os dois proxies selecionados são considerados fatores críticos (Bowman \& Kearney, 1988). Esse é o critério teórico central para a escolha das duas variáveis dependentes a serem analisadas.

Conforme os Relatórios de Progresso do programa destacam, houve "uma visão consolidada dos tributos próprios arrecadados em relação à receita corrente. Observa-se que o nível de arrecadação dos municípios com projeto PNAFM permanece em nível superior $(25,5 \%)$ à média nacional $(19,2 \%)$ nos últimos cinco anos" (MF, 2011, p. 35). Quanto à proporção da Despesa de Pessoal Ativo em relação às Despesa Corrente Realizada, enfatiza-se a sua queda no período de 2002 a 2012.

Ambas variáveis são apresentadas pelo MF (2011) como medidas vitais para qualificar a gestão municipal: mais receitas podem ampliar a autonomia municipal e redução com despesas de pessoal melhora a gestão financeira, considerando os limites estabelecidos pela LRF. As variáveis dependentes foram calculadas com base nos dados Finanças do Brasil da Secretaria do Tesouro Nacional (FINBRA/STN) e IpeaData para os anos de 2001 e 2012. 
A unidade de análise são os municípios com 50 mil ou mais habitantes nos anos de 2001 e 2012, público do PNAFM Ampliado, o que totalizou 1102 cidades (somadas as localidades dos grupos de tratamento e de controle). Adotou-se o ano de 2001 como T0 (antes da entrada no programa) para comparar com 2012 como T1 (após o efeito do programa) 5. Nesse caso, foram realizadas duas comparações: a) municípios antes (T0) e depois (T1); b) 66 municípios do grupo de tratamento (aderiram ao PNAFM até o ano de 2011) e 516 (grupo de controle).

A investigação utilizou um modelo econométrico de painel com efeitos fixos (pelo teste de Hausmann pode-se rejeitar a hipótese nula em favor da hipótese alternativa para este tipo de painel). O painel consiste em comparar, através do tempo, o mesmo grupo de municípios, sendo que alguns foram expostos ao programa e outros não. Excetuada essa diferença, as mesmas variáveis de controle são aplicadas para ambos os grupos, de modo que se pode comparar participantes e não-participantes do PNAFM em dois períodos de tempo (antes e após o efeito do programa). O modelo subtrai duas diferenças (grupo de tratamento e grupo de controle; antes e depois do programa) (Angrist \& Pischcke, 2008). Inserem-se nesse modelo duas variáveis dummy $(=1)$ para os participantes e $(=1)$ para o período posterior ao tratamento.

O principal resultado que se busca é o efeito do tratamento no tempo, o que é obtido gerando uma interação das duas variáveis dummy (tratamento* tempo). A variável de interação diff busca capturar, comparando médias antes/depois e controle/tratamento, qual seria o comportamento do contrafactual (municípios tratados caso não ingressassem no PNAFM) e do grupo de controle. Assim, testa-se essa hipótese nula contra a hipótese alternativa que o PNAFM, na média, alterou a trajetória dos municípios entre 2001 e 2012.

Para Angrist e Pischcke (2008), o pressuposto-chave é que o comportamento das variáveis de interesses seria o mesmo para todos os municípios na ausência do tratamento. $O$ tratamento induz um desvio na trajetória e, embora o grupo tratado possa diferir do controle, essa diferença seria explicada pelas características dos municípios que jogam o papel de efeitos inobserváveis nos dois períodos. A tabela 1 apresenta as covariáveis que serão utilizadas no painel. 
Tabela 1: Variáveis de controle utilizadas na construção do banco de dados

\begin{tabular}{|c|c|c|c|}
\hline Variáveis & Descrições & Período & Fonte \\
\hline $\operatorname{IDHM}(0$ a 1$)$ & $\begin{array}{l}\text { Índice de Desenvolvimento } \\
\text { Humano Municipal }\end{array}$ & $\begin{array}{l}2000 \text { e } \\
2010\end{array}$ & PNUD \\
\hline $\begin{array}{l}\text { Renda até } 1 \\
\text { Salário Mínimo } \\
\text { dos ocupados } \\
\text { com } 18 \text { ou mais } \\
\text { anos }(\%)\end{array}$ & $\begin{array}{l}\text { População que recebe até } 1 \\
\text { salário minimo }\end{array}$ & $\begin{array}{l}2000 \mathrm{e} \\
2010\end{array}$ & PNUD \\
\hline $\begin{array}{l}\text { Escolaridade } \\
\text { superior da } \\
\text { população } \\
\text { ocoupada (\%) }\end{array}$ & $\begin{array}{l}\text { População com ensino } \\
\text { universitário }\end{array}$ & $\begin{array}{l}2001 \text { e } \\
2010\end{array}$ & PNUD \\
\hline Formalização (\%) & $\begin{array}{l}\text { Grau de formalização do } \\
\text { emprego }\end{array}$ & $\begin{array}{l}2000 \text { e } \\
2010\end{array}$ & PNUD \\
\hline $\begin{array}{l}\text { Índice de Gini (0 } \\
\text { a 1) }\end{array}$ & Grau de desigualdade social & $\begin{array}{l}2000 \text { e } \\
2010\end{array}$ & PNUD \\
\hline Pobres (\%) & População pobre & $\begin{array}{l}2000 \text { e } \\
2010\end{array}$ & PNUD \\
\hline $\begin{array}{l}\text { Desocupação } \\
\text { (taxa) }\end{array}$ & $\begin{array}{l}\text { Desocupados com mais de } 18 \\
\text { anos }\end{array}$ & $\begin{array}{l}2000 \text { e } \\
2010\end{array}$ & PNUD \\
\hline $\begin{array}{l}\text { Servidores } \\
\text { públicos (taxa) }\end{array}$ & $\begin{array}{l}\text { Servidores públicos por } 1000 \\
\text { habitantes }\end{array}$ & $\begin{array}{l}2000 \text { e } \\
2010\end{array}$ & PNUD \\
\hline $\begin{array}{l}\text { Veiculos } \\
\text { (número } \\
\text { absoluto) }\end{array}$ & Frota municipal de veiculos & $\begin{array}{l}2001 \text { e } \\
2012\end{array}$ & DENATRAN \\
\hline $\begin{array}{l}\text { PIB Municipal } \\
\text { (valores em } \\
\text { moeda nacional) }\end{array}$ & $\begin{array}{l}\text { Produto Interno Bruto dos } \\
\text { municipios }\end{array}$ & $\begin{array}{l}2001 \text { e } \\
2012\end{array}$ & IBGE \\
\hline $\begin{array}{l}\text { População } \\
\text { (número } \\
\text { absoluto) }\end{array}$ & População dos municípios & $\begin{array}{l}2001 \text { e } \\
2010\end{array}$ & IBGE \\
\hline PNAFM & $\begin{array}{l}\text { Dummy } 1 \text {, se participou, } 0 \mathrm{se} \\
\text { não participou }\end{array}$ & $\begin{array}{l}2001 \text { e } \\
2012\end{array}$ & $\begin{array}{l}\text { Minist. } \\
\text { Fazenda }\end{array}$ \\
\hline Tempo & $\begin{array}{l}\text { Dummy 1, para depois (2012) e } \\
0 \text { para antes (2001) }\end{array}$ & $\begin{array}{l}2001 \text { e } \\
2012\end{array}$ & $\begin{array}{l}\text { Minist. } \\
\text { Fazenda }\end{array}$ \\
\hline Diff & $\begin{array}{l}\text { Interação das variáveis PNAFM } \\
\text { e Tempo }\end{array}$ & & $\begin{array}{l}\text { Elaboração } \\
\text { própria }\end{array}$ \\
\hline
\end{tabular}

Fonte: elaborado pelo autor.

Variáveis independentes

A principal variável de interesse é a adesão municipal ao PNAFM. Busca-se identificar se a organização do programa por subgovernments (Wright, 1988; Peters, 2015), como são MF e CEF, promoveu capacidade estatal municipal por meio da cooperação federativa (Elazar, 1987; Agranoff, 2001) e difusão vertical do programa (Biersboek, Peters, \& Tosun, 2017; Kim et al., 2018; Peters, 2015). É uma variável dummy $(1=$ participou e $0=$ não participou).

Variáveis dependentes

Duas são as variáveis de capacidade estatal municipal. A primeira, despesas com recursos humanos (Evans, 2003; Grindle, 1996; Olsen, 2005). Para essa variável espera-se um sinal negativo (-), de forma que a adesão ao programa gere uma redução com os gastos de pessoal. A segunda, obtenção de receita tributária própria (Luna \& Soifer, 2017; Wolman, McManmon, Bell, \& Brunori, 2010). Para essa variável espera-se um sinal positivo (+), de modo que a participação no programa amplie a receita própria. Ambos objetivos estão entre aqueles buscados pelo PNAFM, conforme já destacado.

Variáveis de controle 
A seleção das variáveis de controle foi organizada considerando um conjunto de fatores que também podem impactar e explicar a realidade das finanças municipais. Estes estão divididos em dois grupos. O primeiro, os fatores contextuais de cunho socioeconômico, demográfico e econômico que podem impactar as finanças municipais. Por exemplo, menor desenvolvimento humano se associa com menor qualidade educacional, o que afeta o valor dos salários da força de trabalho e pode reduzir os tributos locais. Maiores taxas de informalidade produzem o mesmo efeito, assim como o porcentual dos que recebem até um salário mínimo. O segundo, os fatores relacionados à realidade administrativa, como é o caso das capacidades burocráticas, que são associadas com as competências técnicas que influenciam a performance da gestão municipal.

Quanto aos fatores contextuais relacionados, Enriquez e Centeno (2012) destacam a importância daqueles de cunho econômico e socieconômico:

a) Variáveis socioeconômicas: Índice de Desenvolvimento Humano Municipal (IDHM), Índice de Gini (Ind_Gini), porcentual de pobres (Pop_Pobre) e porcentual da população acima de 18 anos com renda de até um salário mínimo (\%_Renda_1SM): o pressuposto é que maior IDHM impacta positivamente a capacidade estatal, enquanto maior concentração de renda local, existência de população pobre e daqueles auferindo salários de até 1 salário mínio (SM) geram efeitos negativos.

b) Demográficas: porte populacional total (Pop_total): quanto maior for, maior a possibilidade de arrecadação e de boa gestão de recursos humanos.

c) Econômicas: PIB Municipal (PIB_Munic), formalização da mão de obra (Formaliza_Trabalho), população economicamente ativa (PEA) desocupada acima de 18 anos (Tx_Desocupa_18_anos) e frota local de veículos (Frota_veículos): exceto a desocupação da força de trabalho que produz consequências negativas sobre a gestão municipal, nas demais variáveis a associação esperada é positiva com o aumento das capacidades estatais.

No segundo grupo, variáveis de capacidade estatal (Andrew, 2009; Bel \& Warner, 2016; Meza, Grin, Fernandes, \& Abrucio, 2019):

a) População com ensino superior (Pop_Ocup_Nivel_Superior): proxy de educação formal dos servidores públicos municipais, de forma que se espera uma associação positiva.

b) Taxa de servidores em relação a população local (Tx_Trab_Pub): a associação esperada pode ser positiva ou negativa, pois não há parâmetro definido em termos quantitativos.

Considerando esse conjunto de variáveis, seguem as estatísticas descritivas (tabela 2). 
Tabela 2: Estatísticas descritivas

\begin{tabular}{|c|c|c|c|c|c|}
\hline Variáveis & Obs. & Média & $\begin{array}{l}\text { Desvio } \\
\text { Padrão }\end{array}$ & Minímo & Máximo \\
\hline \multicolumn{6}{|l|}{ Variáveis dependentes } \\
\hline Taxa de despesa pessoal & 1.102 & 0,58 & 0,20 & 0,008 & 1 \\
\hline Taxa de arrecadação própria & 1.102 & 0,11 & 0,08 & 0,00024 & 0,49 \\
\hline \multicolumn{6}{|l|}{ Variável independente } \\
\hline Diff & 1.102 & 0,06 & 0,237 & 0 & 1 \\
\hline \multicolumn{6}{|l|}{ Variáveis de controle } \\
\hline$\%$ Renda_1SM $18+$ anos & 1.102 & 33,2 & 21,65 & 4,53 & 92,61 \\
\hline Pop_Ocupada_Nivel_Superior & 1.102 & 8,82 & 5,67 & 0 & 37,53 \\
\hline Formaliza_Trabalho & 1.102 & 55,9 & 17,02 & 7,03 & 84,16 \\
\hline IDHM & 1.102 & 0,67 & 0,096 & 0,28 & 0,862 \\
\hline Ind_Gini & 1.102 & 0,53 & 0,059 & 0,35 & 0,72 \\
\hline Pop_Pobre & 1.102 & 19,9 & 17,39 & 0,52 & 78,48 \\
\hline Tx Desocupa_18_anos & 1.102 & 10,9 & 5,112 & 1,70 & 28,24 \\
\hline Tx_Trab_Pub & 1.102 & 5,36 & 2,606 & 0,46 & 23,49 \\
\hline Frota_Veículos & 1.102 & 7.1275 & 27.1986 & 111 & 6.795228 \\
\hline PIB_Munic (log) & 1.102 & 20,82 & 1,40 & 15,47 & 26,93 \\
\hline
\end{tabular}

Fonte: elaborado pelo autor

(1) O valor do VIF é de 5,3, o que indica não existir níveis significativos de multicolinearidade.

\section{Resultados dos PAINÉIS SOBRE o PNFAM E CAPACIDADES ESTATAis MUNiCiPAis}

A avaliação dos contratos do programa (Fase I e Fase II) baseia-se em indicadores de impacto que tiveram sua evolução semestral apresentada nos Relatórios de Progresso da UCP entre 2002 e 2011 . Será avaliado apenas o PNAFM Ampliado e a Fase II (aplicável para 66 municípios com mais de 50 mil habitantes dos quais há dados disponíveis para os dois períodos)8. Os Relatórios apresentam indicadores de impacto em áreas-chave (receita própria, despesas e gestão de pessoas). Nesta pesquisa, serão utilizados dois parâmetros para essa avaliação: taxa de despesa do pessoal ativo e taxa de arrecadação própria, ambas para 2001 e 2012. Os Relatórios de Progresso comparam médias dos indicadores entre municípios participantes (azul nos gráficos) e o restante das localidades (vermelho nos gráficos).

\subsection{Gestão de pessoas}

Quanto à despesa com pessoal, que consta dos Relatórios de Progresso até 2011, a figura 2 e a tabela 3 mostram os resultados nos municípios. 


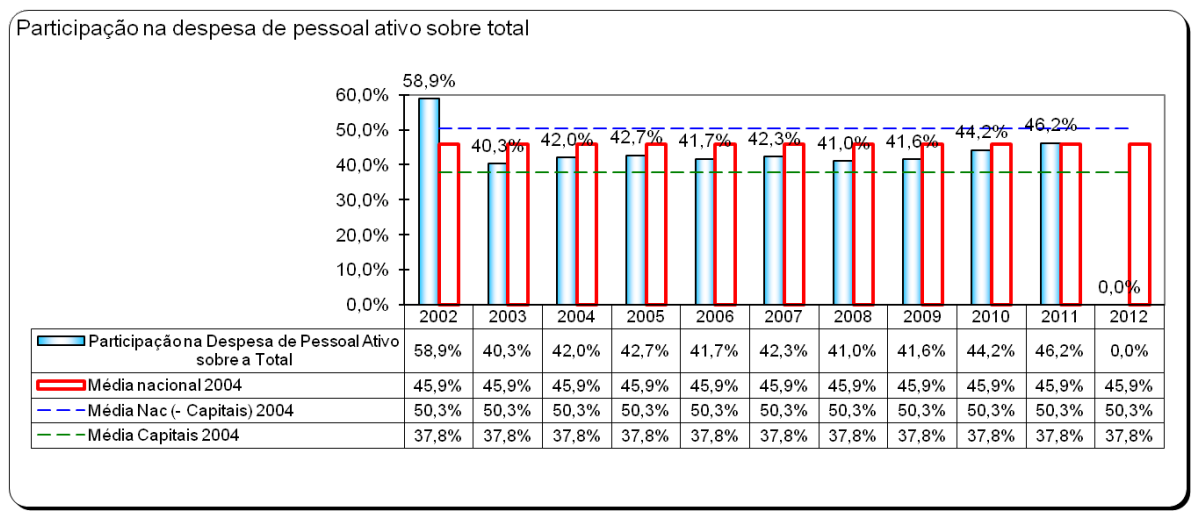

FIGURA 2

Participação na despesa de pessoal ativo despesa com pessoal ativodespesa corrente realizada Fonte: Relatório de Progresso UCP/MF (junho/dezembro de 2011) (MF, 2011).

Pela informação apresentada no Relatório, os municípios do PNAFM não se distinguem muito da média nacional, mas esse procedimento não define um T0 antes de o PNAFM ter iniciado, tampouco introduz um modelo de análise com covariáveis para controlar seu efeito, pois pode ser que outros aspectos sejam responsáveis pelos valores alcançados no quesito "despesa com pessoal ativo". De 2001 a 2012, o programa não gerou resultados que possam ser tributados como efeito de sua ação, conforme os resultados apresentados na tabela 3.

No que tange à despesa com pessoal, os avanços foram muito pequenos, mesmo considerando a evolução em 12 anos dos valores gastos em relação à despesa total. Quando o painel testa o efeito da principal variável de interesse (Diff), estatisticamente evidencia-se que, dada a trajetória quase constante de despesa com pessoal, o programa não é uma variável que tenha contribuído para alterar esse quadro, considerando os valores médios dos gastos de todos os municípios que o contrataram como uma referência comparativa. Pelo contrário, os municípios participantes do programa ampliaram seus gastos com pessoal em comparação com aqueles do grupo de tratamento. A associação positiva entre Diff e despesa de pessoal evidencia esse resultado. $\mathrm{O}$ desempenho do programa apresentou um comportamento contrário ao esperado, ainda que estatisticamente significante em todos os modelos.

Em relação as variáveis contextuais demográficas e socioeconômicas, população do município é estatisticamente significante ( $\mathrm{p}<0.05 \mathrm{em}$ dois modelos e $\mathrm{p}<0.10 \mathrm{em}$ um modelo) e com sinal negativo: cidades reduzem sua despesa com pessoal conforme aumentam sua população, o que está em linha com a literatura (Grin \& Abrucio, 2018a). O Índice de Desenvolvimento Humano Municipal (IDHM) é positivamente associado com a despesa de pessoal a $0.01 \mathrm{em}$ todos os modelos, enquanto Ind_Gini apresenta um sinal negativo, mas significante a $\mathrm{p}<0.001$. Assim, maiores níveis de desenvolvimento local e de concentração de renda estão associados com mais gastos com pessoal. Quanto maior o contingente populacional que tem renda de até $1 \mathrm{SM}$, menor o gasto com servidores públicos. Contudo, maiores parcelas de população pobre incrementam as despesas com pessoal.

No campo das variáveis econômicas, o produto interno bruto (PIB) municipal é positivamente associado ao gasto com pessoal ( $\mathrm{p}<0.01)$ em todos os modelos: mais riqueza local, mais despesas com servidores. A frota de veículos não é estatisticamente significante. Taxa de desocupação e formalização da força de trabalho são significantes $(\mathrm{p}<0.01)$ em todos os modelos, mas com sinal negativo. Faz sentido que mais formalização da mão de obra reduza gastos públicos, mas o mesmo não se explica se o desemprego aumenta. Ainda que esse seja um resultado contraintuitivo, esta pesquisa não irá analisá-lo.

Com relação às variáveis de capacidade estatal, taxa de servidores públicos não está associada com os gastos de pessoal. O nível de escolaridade superior nas cidades é significante em um modelo ( $\mathrm{p}<0.01)$. Em resumo, variáveis desse grupo são pouco representativas para explicar o comportamento das despesas com servidores. 
Eduardo José Grin. O verso e o reverso da cooperação federativa E da difusão vertical de políticas...

Tabela 2: Resultados do painel sobre a despesa de pessoal ativo/despesa total (municípios +50 mil hab.)

\begin{tabular}{|c|c|c|c|c|}
\hline Variáveis & (1) & (2) & (3) & (4) \\
\hline Diff & $\begin{array}{l}0.0488^{*} \\
(0.0284)\end{array}$ & $\begin{array}{l}0.0466^{*} \\
(0.0276)\end{array}$ & $\begin{array}{l}0.0619 * * \\
(0.0291)\end{array}$ & $\begin{array}{l}0.0385 \\
(0.0259)\end{array}$ \\
\hline Pop_Total (log) & $\begin{array}{l}-0.00206 \\
(0.0104)\end{array}$ & $\begin{array}{l}-0.0228^{* *} \\
(0.0102)\end{array}$ & $\begin{array}{l}-0.0214^{* *} \\
(0.0108)\end{array}$ & $\begin{array}{l}-0.0159 * \\
(0.00961)\end{array}$ \\
\hline Ind_Gini & $\begin{array}{l}-1.192^{* * *} \\
(0.154)\end{array}$ & $\begin{array}{l}-0.581^{* * * *} \\
(0.160)\end{array}$ & $\begin{array}{l}-0.676^{* * *} \\
(0.169)\end{array}$ & $\begin{array}{l}-0.644^{* * *} \\
(0.150)\end{array}$ \\
\hline IDHM & $\begin{array}{l}2.649 * * * \\
(0.212)\end{array}$ & & $\begin{array}{l}0.727^{* * * *} \\
(0.213)\end{array}$ & $\begin{array}{l}1.806^{* * *} \\
(0.210)\end{array}$ \\
\hline _Renda_1SM & & $\begin{array}{l}-0.0112 * * * \\
(0.000807)\end{array}$ & $\begin{array}{l}-0.00522 * * * \\
(0.000874)\end{array}$ & $\begin{array}{l}-0.00842^{* * *} \\
(0.000821)\end{array}$ \\
\hline Pop_Pobre & $\begin{array}{l}0.00965^{* * * *} \\
(0.00119)\end{array}$ & $\begin{array}{l}0.00924^{* * *} \\
(0.00110)\end{array}$ & & $\begin{array}{l}0.0135^{* * *} \\
(0.00115)\end{array}$ \\
\hline Pib_Munic (log) & $\begin{array}{l}0.0138 * * * \\
(0.00484)\end{array}$ & $\begin{array}{l}0.0168 * * * \\
(0.00466)\end{array}$ & $\begin{array}{l}0.0225^{* * *} \\
(0.00485)\end{array}$ & $\begin{array}{l}0.0105^{* *} \\
(0.00442)\end{array}$ \\
\hline Frota_Veiculos & $\begin{array}{l}7.65 e-09 \\
(2.73 e-08)\end{array}$ & $\begin{array}{l}-1.04 \mathrm{e}-08 \\
(2.65 \mathrm{e}-08)\end{array}$ & $\begin{array}{l}-1.08 \mathrm{e}-08 \\
(2.80 \mathrm{e}-08)\end{array}$ & $\begin{array}{l}5.07 \mathrm{e}-09 \\
(2.48 \mathrm{e}-08)\end{array}$ \\
\hline Tx_Desocupa_18_anos & $\begin{array}{l}-0.0110^{* * *} \\
(0.00169)\end{array}$ & $\begin{array}{l}-0.0129 * * * \\
(0.00161)\end{array}$ & $\begin{array}{l}-0.00967^{* * *} \\
(0.00174)\end{array}$ & $\begin{array}{l}-0.00990 * * * \\
(0.00155)\end{array}$ \\
\hline Formaliza_Trabalho & $\begin{array}{l}-0.00303^{* * *} \\
(0.000921)\end{array}$ & $\begin{array}{l}-0.00410 * * * \\
(0.000898)\end{array}$ & $\begin{array}{l}-0.00858 * * * \\
(0.000826)\end{array}$ & $\begin{array}{l}-0.00369 * * * \\
(0.000842)\end{array}$ \\
\hline Tx_Trab_Pub & $\begin{array}{l}-0.00195 \\
(0.00266)\end{array}$ & $\begin{array}{l}-0.00167 \\
(0.00259)\end{array}$ & $\begin{array}{l}-0.00165 \\
(0.00274)\end{array}$ & $\begin{array}{l}-0.00253 \\
(0.00243)\end{array}$ \\
\hline _Pop_Ocup_Nivel_Superior & $\begin{array}{l}-0.00175 \\
(0.00244)\end{array}$ & $\begin{array}{l}0.00789 * * * \\
(0.00206)\end{array}$ & $\begin{array}{l}0.00340 \\
(0.00247)\end{array}$ & $\begin{array}{l}-0.00166 \\
(0.00223)\end{array}$ \\
\hline Constante & $\begin{array}{l}-0.691^{* * * *} \\
(0.222)\end{array}$ & $\begin{array}{l}1.302^{* * *} \\
(0.167)\end{array}$ & $\begin{array}{l}0.973^{* * * *} \\
(0.225)\end{array}$ & $\begin{array}{l}0.0392 \\
(0.215)\end{array}$ \\
\hline Observações & 1,102 & 1,102 & 1,102 & 1,102 \\
\hline R-quadrado & 0.719 & 0.733 & 0.703 & 0.767 \\
\hline
\end{tabular}

Erros padrão entre parênteses: $\left.{ }^{* * *} \mathrm{p}<0.01,{ }^{* *} \mathrm{p}<0.05,{ }^{*} \mathrm{p}<0.1\right)$ 


\begin{tabular}{|c|c|c|c|c|}
\hline & (1) & $(2)$ & (3) & (4) \\
\hline Variáveis & Grau_desp_pessoal & Grau_desp_pessoal & Grau_desp_pessoal & Grau_desp_pessoal \\
\hline \multirow[t]{2}{*}{ Diff } & $0.0488 *$ & $0.0466^{*}$ & $0.0619 * *$ & 0.0385 \\
\hline & $(0.0284)$ & $(0.0276)$ & $(0.0291)$ & $(0.0259)$ \\
\hline \multirow[t]{2}{*}{ Pop_Totall } & -0.00206 & $-0.0228^{* *}$ & $-0.0214 * *$ & $-0.0159 *$ \\
\hline & $(0.0104)$ & $(0.0102)$ & $(0.0108)$ & $(0.00961)$ \\
\hline \multirow[t]{2}{*}{ Ind_Gini } & $-1.192 * * *$ & $-0.581^{* * *}$ & $-0.676^{* * *}$ & $-0.644 * * *$ \\
\hline & $(0.154)$ & $(0.160)$ & $(0.169)$ & $(0.150)$ \\
\hline \multirow[t]{2}{*}{ IDHM } & $2.649 * * *$ & & $0.727^{* * *}$ & $1.806^{* * * *}$ \\
\hline & $(0.212)$ & & $(0.213)$ & $(0.210)$ \\
\hline \multirow[t]{2}{*}{ Renda_1SM } & & $-0.0112^{* * *}$ & $-0.00522 * * *$ & $-0.00842^{* * *}$ \\
\hline & & $(0.000807)$ & $(0.000874)$ & $(0.000821)$ \\
\hline \multirow[t]{2}{*}{ Pop_Pobre } & $0.00965^{* * *}$ & $0.00924 * * *$ & & $0.0135^{* * *}$ \\
\hline & $(0.00119)$ & $(0.00110)$ & & $(0.00115)$ \\
\hline \multirow[t]{2}{*}{ Pib_Munic1 } & $0.0138 * * *$ & $0.0168^{* * *}$ & $0.0225^{* * *}$ & $0.0105^{* *}$ \\
\hline & $(0.00484)$ & $(0.00466)$ & $(0.00485)$ & $(0.00442)$ \\
\hline \multirow[t]{2}{*}{ Frota_Veiculos } & $7.65 e-09$ & $-1.04 \mathrm{e}-08$ & $-1.08 \mathrm{e}-08$ & $5.07 e-09$ \\
\hline & $(2.73 e-08)$ & $(2.65 \mathrm{e}-08)$ & $(2.80 \mathrm{e}-08)$ & $(2.48 \mathrm{e}-08)$ \\
\hline \multirow[t]{2}{*}{ Tx_Desocupa_18_anos } & $-0.0110^{* * *}$ & $-0.0129 * * *$ & $-0.00967 * * *$ & $-0.00990 * * *$ \\
\hline & $(0.00169)$ & $(0.00161)$ & $(0.00174)$ & $(0.00155)$ \\
\hline \multirow[t]{2}{*}{ Formaliza_Trabalho } & $-0.00303^{* * *}$ & $-0.00410 * * *$ & $-0.00858 * * *$ & $-0.00369 * * *$ \\
\hline & $(0.000921)$ & $(0.000898)$ & $(0.000826)$ & $(0.000842)$ \\
\hline \multirow[t]{2}{*}{ Tx_Trab_Pub } & -0.00195 & -0.00167 & -0.00165 & -0.00253 \\
\hline & $(0.00266)$ & $(0.00259)$ & $(0.00274)$ & $(0.00243)$ \\
\hline \multirow[t]{2}{*}{ _Pop_Ocup_Nivel_Superior } & -0.00175 & $0.00789 * * *$ & 0.00340 & -0.00166 \\
\hline & $(0.00244)$ & $(0.00206)$ & $(0.00247)$ & $(0.00223)$ \\
\hline \multirow[t]{2}{*}{ Constant } & $-0.691 * * *$ & $1.302 * * *$ & $0.973^{* * *}$ & 0.0392 \\
\hline & $(0.222)$ & $(0.167)$ & $(0.225)$ & $(0.215)$ \\
\hline Observations & 1,102 & 1,102 & 1,102 & 1,102 \\
\hline R-squared & 0.719 & 0.733 & 0.703 & 0.767 \\
\hline Number of Cod & 580 & 580 & 580 & 580 \\
\hline
\end{tabular}

${ }^{* * *} \mathrm{p}<0.01,{ }^{* *} \mathrm{p}<0.05,{ }^{*} \mathrm{p}<0.1$

(1) $\mathrm{N}=1102$ municípios, incluídos os 132 do grupo de tratamento (66 antes e depois).

(2) Os quatro modelos foram elaborados da seguinte forma: a) retirando variáveis cuja correlação (acima de 0.8 ) alta poderia indicar multicolinearidade; b) um modelo com todas as variáveis.

\subsection{Receitas próprias}

Quanto ao aumento da receita própria, essa era a meta central do PNFAM, visando a expandir a autonomia municipal em relação às transferências federais (figura 3). 


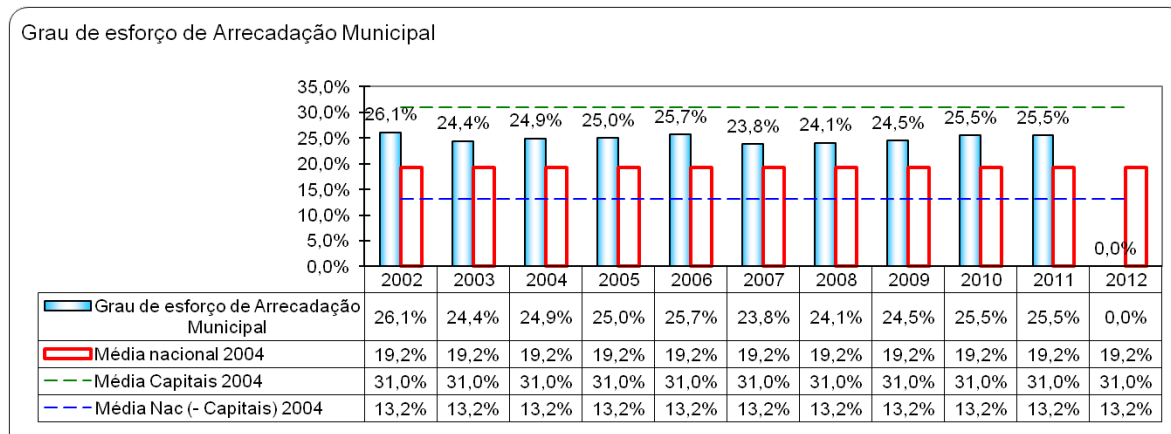

FIGURA 3

Esforço de arrecadação municipal receita tributária própria realizadareceita corrente realizada Fonte: Relatório de Progresso UCP/MF (junho/dezembro de 2011). (MF, 2011).

Ainda que diante da média nacional os resultados dos Relatórios de Progresso sejam significativos para as cidades que contrataram o PNAFM, os dados do painel na tabela 4 mostram que esse avanço não está associado ao programa. Pelo contrário, para os municípios que aderiram ao programa houve uma redução na ampliação da receita própria, o que revela um comportamento contrário esperado para essa variável. O sinal negativo da variável Diff em todos os modelos ( $\mathrm{p}<0.05$ em um modelo e $\mathrm{p}<0.10$ em outros três) mostra esse resultado. Com efeito, não apenas o programa não incrementou as receitas locais, como reduziu sua expansão nas cidades que o contrataram.

A variável população municipal é significante em todos os modelos $(\mathrm{p}<0.01)$, o que está de acordo com a literatura. No bloco das variáveis socioeconômicas, maiores níveis de IDHM não são associados com aumento da receita municipal. Os resultados para o Ind_Gini são contra intuitivos, pois se esperaria uma associação negativa. Uma possível explicação seria: cidades onde a concentração de renda é maior, o que geralmente se associa com desigualdade social induzem os governos a arrecadarem mais tributos para fazer frente às demandas ampliadas por políticas públicas. Ademais, em geral, cidades com maiores porte populacionais costumam deter maiores capacidades estatais (Grin \& Fernandes, 2019). Maiores porcentuais de renda até 1 SM e de Pop_pobre impactam negativamente a arrecadação própria $(\mathrm{p}<0.01 \mathrm{em}$ todos os modelos nas duas variáveis).

O grupo das variáveis econômicas mostra que a maior a formalização do trabalho (p. $<0.01$ ), cresce a possibilidade de incrementar a parcela dos impostos locais no orçamento do município, como é o caso do Imposto sobre Serviços (ISS) e do Imposto Predial e Territorial Urbano (IPTU) comercial. A taxa de desocupação da população acima de 18 anos também apresenta uma associação contra intuitiva, pois esta é positiva a $\mathrm{p}<0.01$ em todos os modelos. O Pib_Munic e formalização do trabalho não apresentam qualquer nível mínimo de significância estatística. Frota de veículos na cidade, que também é um proxy de atividade econômica, é positivamente associado $(\mathrm{p}<0.01)$ em todos os modelos, o que faz sentido. A variável taxa de desocupados apresenta um resultado contraintuitivo, pois seu sinal é positivo $(\mathrm{p}<0.01)$ em todos os modelos. 
Tabela 4: Resultados do painel sobre arrecadação própria (municípios acima de 50 mil hab.)

\begin{tabular}{|c|c|c|c|c|}
\hline Variáveis & (1) & (2) & (3) & (4) \\
\hline Diff & $\begin{array}{l}-0.0213^{*} \\
(0.0109)\end{array}$ & $\begin{array}{c}-0.0198 * \\
(0.0110)\end{array}$ & $\begin{array}{l}-0.0231^{* *} \\
(0.0109)\end{array}$ & $\begin{array}{l}-0.0212^{*} \\
(0.0109)\end{array}$ \\
\hline Pop_Total (log) & $\begin{array}{l}0.0162 * * * \\
(0.00403)\end{array}$ & $\begin{array}{l}0.0180 * * * \\
(0.00404)\end{array}$ & $\begin{array}{l}0.0166^{* * *} \\
(0.00406)\end{array}$ & $\begin{array}{l}0.0162 * * * \\
(0.00405)\end{array}$ \\
\hline Ind_Gini & $\begin{array}{l}0.185^{* * *} \\
(0.0629)\end{array}$ & $\begin{array}{l}0.111^{*} \\
(0.0595)\end{array}$ & $\begin{array}{l}0.188^{* * *} \\
(0.0633)\end{array}$ & $\begin{array}{l}0.185^{* * *} \\
(0.0631)\end{array}$ \\
\hline IDHM & & $\begin{array}{l}0.107 \\
(0.0822)\end{array}$ & $\begin{array}{l}0.0782 \\
(0.0800)\end{array}$ & $\begin{array}{l}-0.00741 \\
(0.0885)\end{array}$ \\
\hline _Renda_1SM & $\begin{array}{l}-0.00113^{* * *} \\
(0.000318)\end{array}$ & & $\begin{array}{l}-0.00139 * * * \\
(0.000328)\end{array}$ & $\begin{array}{l}-0.00114^{* * *} \\
(0.000346)\end{array}$ \\
\hline Pop_Pobre & $\begin{array}{l}-0.00106^{* *} \\
(0.000434)\end{array}$ & $\begin{array}{l}-0.00160 * * * \\
(0.000460)\end{array}$ & & $\begin{array}{l}-0.00107 * * \\
(0.000482)\end{array}$ \\
\hline Pib_Munic (log) & $\begin{array}{l}-0.00148 \\
(0.00183)\end{array}$ & $\begin{array}{l}-0.00101 \\
(0.00187)\end{array}$ & $\begin{array}{l}-0.00242 \\
(0.00182)\end{array}$ & $\begin{array}{l}-0.00146 \\
(0.00186)\end{array}$ \\
\hline Frota_Veiculos & $\begin{array}{l}3.84 \mathrm{e}-08^{* * *} \\
(1.04 \mathrm{e}-08)\end{array}$ & $\begin{array}{l}3.87 \mathrm{e}-08^{* * *} \\
(1.06 \mathrm{e}-08)\end{array}$ & $\begin{array}{l}3.96 \mathrm{e}-08^{* * * *} \\
(1.05 \mathrm{e}-08)\end{array}$ & $\begin{array}{l}3.83 \mathrm{e}-08^{* * *} \\
(1.05 \mathrm{e}-08)\end{array}$ \\
\hline Tx_Desocupa_18_anos & $\begin{array}{l}0.00258^{* * *} \\
(0.000634)\end{array}$ & $\begin{array}{l}0.00242^{* * *} \\
(0.000656)\end{array}$ & $\begin{array}{l}0.00255^{* * *} \\
(0.000654)\end{array}$ & $\begin{array}{l}0.00257^{* * *} \\
(0.000652)\end{array}$ \\
\hline Formaliza_Trabalho & $\begin{array}{l}-0.000301 \\
(0.000353)\end{array}$ & $\begin{array}{l}-0.000213 \\
(0.000357)\end{array}$ & $\begin{array}{l}8.60 \mathrm{e}-05 \\
(0.000309)\end{array}$ & $\begin{array}{l}-0.000303 \\
(0.000354)\end{array}$ \\
\hline Tx_Trab_Pub & $\begin{array}{l}-0.00491^{* * *} \\
(0.00102)\end{array}$ & $\begin{array}{l}-0.00483^{* * *} \\
(0.00103)\end{array}$ & $\begin{array}{l}-0.00497^{* * *} \\
(0.00103)\end{array}$ & $\begin{array}{l}-0.00490 * * * \\
(0.00102)\end{array}$ \\
\hline _Pop_Ocup_Nivel_Superior & $\begin{array}{l}0.00406^{* * *} \\
(0.000812)\end{array}$ & $\begin{array}{l}0.00409 * * * \\
(0.000947)\end{array}$ & $\begin{array}{l}0.00370^{* * * *} \\
(0.000924)\end{array}$ & $\begin{array}{l}0.00410^{* * *} \\
(0.000938)\end{array}$ \\
\hline Constant & $\begin{array}{l}-0.108 \\
(0.0657)\end{array}$ & $\begin{array}{l}-0.202^{* *} \\
(0.0860)\end{array}$ & $\begin{array}{l}-0.177^{* *} \\
(0.0843)\end{array}$ & $\begin{array}{l}-0.103 \\
(0.0903)\end{array}$ \\
\hline Observations & 1,102 & 1,102 & 1,102 & 1,102 \\
\hline R-quadrado & 0.575 & 0.566 & 0.571 & 0.575 \\
\hline
\end{tabular}

As variáveis sobre a burocracia municipal mostram que contingentes maiores de pessoas com educação superior aumenta as possibilidades arrecadatórias $(\mathrm{p}<0.01 \mathrm{em}$ todos os modelos) e que taxas maiores de servidores públicos reduzem o incremento dos tributos próprios, também com coeficiente de $\mathrm{p}<0.01$.

\section{Discuss Ão dos Resultados}

Comparando os municípios participantes com os não participantes, as diferenças entre os dois grupos e entre esses no tempo apresenta efeito estatístico significante, mas com sinais contrários ao esperado nas duas variáveis testadas. Portanto, não apenas o PNAFM não gerou resultados quanto ao aumento de receitas próprias e redução de despesas com pessoal para as localidades que aderiram ao programa como piorou sua performance. Entre 2001 e 2012, o PNFAM não teve impacto na performance nas variáveis discutidas, de forma que não se pode afirmar que o programa gerou capacidades estatais municipais nessas dimensões de análise.

Como esse foi um programa concebido de forma centralizada, e mesmo que tenha se direcionado para os maiores municípios com população acima de 50 mil habitantes, constata-se que a assimetria de acesso em 
favor desses não teve contrapartida na melhoria da sua gestão. Sob o prisma das relações intergovernamentais, essa é uma má inferência, pois com esse tipo de modelo organizacional, programas federais construídos podem fracassar na promoção de capacidades estatais municipais.

Este trabalho iniciou perguntando-se se a cooperação federativa (Elazar, 1987), por meio de programas federais (Agranoff, 2001; Elazar, 1962; Skocpol, 2002) voltados a qualificar as capacidades estatais em municípios e apoiados em instrumentos de difusão vertical de políticas (Kim et al., 2018), é capaz de alcançar resultados positivos. Como constatado ao longo da discussão, as evidências empíricas dão suporte ao argumento proposto, em linha com a literatura utilizada.

Mesmo que os Relatórios de Progressos do MF não demonstrassem progressos significativos em 12 anos, ainda assim é importante avaliar estatisticamente se, para as localidades participantes, o programa teve impacto positivo. Nas duas hipóteses (gestão da despesa com pessoal e ampliação da receita tributária própria) os resultados confirmam o argumento teórico proposto. Com efeito, o que explicou a performance da gestão municipal quanto aos gastos com pessoal e ampliação da receita própria foram os "fatores ambientais" (Enriquez \& Centeno, 2012), demográficos e de gestão municipal (Burgess, 1975).

O PNAFM foi organizado por meio de uma agência federal implementadora (CEF) e uma pasta ministerial gestora (a área fazendária). Uma questão que costuma resultar desse tipo de arranjo institucional é a prevalência das autoridades funcionais (Biesbroek, Peters, \& Tosun, 2018; Peters, 2015). Estas costumam atuar como subgovernments (Wright, 1988) com grande discricionariedade e poder de enforcement. A forma como o programa foi concebido e implantado denota um estilo de política com insulamento do corpo técnico e reduzida cooperação federativa, dadas as características de seu locus institucional (Grin \& Abrucio, 2019; Wright \& Stenberg, 2006) nas agências federais responsáveis.

Estilos de políticas produzem efeitos não apenas em seus instrumentos de implantação, mas também nos resultados que são alcançados. A definição de regras de programas, objetivos a serem atingidos e seleção de públicos-alvo indicam muito sobre suas possibilidades de sucesso. Trajetórias de políticas públicas oriundas de autoridades funcionais geralmente reproduzem seus mecanismos de formulação, controle e difusão vertical. Esse processo tende a gerar resultados alcançados em programas públicos que ficam aquém de suas possibilidades. Todavia, este nem sempre é um critério que influencia mudança de rumos, pois burocracias especializadas podem manter as bases normativas das políticas propostas ao operarem a partir de conjuntos pré-estabelecidos de preferências e meios de implantação (Howlett, 2009; Howlett \& Tosun, 2019; Stead, 2018).

O PNAFM fez escolhas de públicos (foco nos maiores municípios), da difusão vertical (Kim et al., 2018) sem mediação federativa e organizou-se como um programa de assistência direta (Collins, Andrew, \& Khunwishit, 2015) voltado para as localidades que poderiam pagar, mas não para as mais necessitadas de apoio (Grin \& Abrucio, 2017). Assim, além de afastar-se do enorme público potencial dos menores municípios (apenas 23 participantes na versão simplificada), a oferta prioritária para as maiores localidades não logrou bons resultados. Não houve uma acomodação mútua de agendas e de cooperação (Agranoff, 2001) capaz de evidenciar ganhos de capacidade estatal municipal. Os instrumentos de adesão assentados na candidatura voluntária municipal (McDonald \& Gabrini, 2014) mostraram-se insuficientes, mesmo considerando que, em tese, a participação ocorreu com as maiores e mais preparadas cidades em termos administrativos e gerenciais.

Esperava-se que, na média dos municípios participantes, existissem ganhos de capacidade estatal derivados da implantação do PNAFM na gestão de pessoas (Grindle, 1996; Olsen, 2005;), sendo essa variável avaliada pela despesa com pessoal, e na gestão fiscal, mensurada pelo incremento de tributos próprios (Luna \& Soifer, 2017; Wolman, McManmon, Bell, \& Brunori, 2010). Porém, constatou-se que a cooperação intergovernamental baseada na difusão vertical de políticas (Biersboek, Peters, \& Tosun, 2017; Kim et al., 2018; Peters, 2015) e na discricionariedade das agências federais (CEF e MF) não logrou modernizar a gestão 
municipal. Com efeito, o PNAFM não foi capaz de gerar mais capacidade estatal municipal como output, em linha com Glenday (1997).

A cooperação federativa embutida no desenho do PNAFM mostrou-se, considerando a hipótese testada por meio das duas variáveis dependentes, um formato pouco propício à adesão municipal (poucas adesões nos 12 anos analisados), bem como para qualificar seu desempenho administrativo. Menos do que pactuação federativa (Elazar, 1987), o PNAFM esteve mais para o modelo de autoridade inclusiva (Wright, 1988) e da unilateralidade de prioridades oriundas das agências federais (Lae-Cho \& Wright, 2001). Considerando as hipóteses testadas, os dados empíricos evidenciam o quão longe esteve o programa de induzir a qualificação da gestão municipal.

A investigação mostra que autoridades funcionais que possuem grande capacidade de enforcement na implementação de regras de acesso pelas esferas de governo podem ter nesse modelo a receita do insucesso. Sobretudo, essa pode ser a principal consequência em se tratando de programas federais de assistência direta (Collins, Andrew, \& Khunwishit, 2015; McDonald \& Gabrini, 2014). E aqui reside o paradoxo já referido: órgãos especializados na administração federal, mas com capacidade de produzir decisões, podem gerar induções negativas que impactam de forma deletéria a cooperação federativa e os seus resultados. Estilos de difusão de políticas verticais baseados em autoridades funcionais, como ocorreu com o PNAFM, induzem escolhas e o comportamento dos municípios (Kim et al., 2018), ainda que a opção possa ser não adotar um programa federal.

Aa hipóteses analisadas mostram que a construção de capacidades estatais (Evans, 1995; Grindle, 1996; Grin \& Abrucio, 2018b; Olsen, 2005; Rueschemeyer \& Evans, 2002; Schmitter, Wageman, \& Obydenkova, 2005; Sikkink,1991) é pouco provável de ser alcançada com o modelo de difusão vertical de políticas adotado pelo PNAFM. A cooperação federativa para promover capacidades estatais, ao menos nas duas variáveis analisadas, não parece ser uma rota apropriada para lograr êxito nesse objetivo.

Nesse sentido, uma questão que resulta da pesquisa é a importância de considerar os desenhos institucionais e as formas de implementação de arranjos verticais que propõem políticas públicas para outros níveis de governo. Difusão de políticas ocorrem quando escolhas de políticas de um nível de governo afetam as opções de outros entes, o que geralmente envolve vários mecanismos. A seleção dos instrumentos é dirigida por diversas circunstâncias, tais como concepções sobre políticas públicas, recursos disponíveis, obstáculos existentes e arranjos de políticas existentes, afora uma gama de outros fatores intervenientes (Kim \& McDonald, 2016).

A discussão realizada sobre o PNAFM, considerando as variáveis dependentes analisadas, evidencia que essa forma de difusão vertical de políticas precisaria ser repensada em seu desenho institucional para ampliar sua interlocução com os municípios. Esta lacuna de interação entre MF e CEF e as localidades interessadas e não apenas as que contrataram - é um fator importante de ser repensado. Dessa forma, o diálogo federativo poderia ser qualificado para pactuar normas para o programa em conjunto com os municípios.

\section{Conclusão}

Esta pesquisa abordou o tema da cooperação federativa por meio de autoridades funcionais e processos de difusão vertical de políticas, sendo capacidades estatais municipais o foco analítico. Empiricamente a investigação abordou o PNAFM e seu processo de implementação, visando modernizar a gestão municipal, para o que duas variáveis dependentes foram definidas: gastos com pessoal e aumento da receita própria. A conclusão coteja os pressupostos teóricos com o argumento proposto e apresenta os limites e possibilidades desse trabalho.

Como destacado na introdução, a literatura nacional que aborda capacidades estatais municipais vem sendo adensada nos últimos anos. A presente pesquisa se insere nesse campo e busca contribuir com o tema a partir de dois enfoques: a) teoricamente ao abordar a questão pelo prisma da difusão vertical de 
políticas; b) pela análise econométrica realizada que busca avaliar o impacto de um programa federal na gestão municipal, considerando duas variáveis que empiricamente traduzem argumentos teóricos da literatura sobre capacidades estatais.

Estudos de caso são importantes para propor perguntas aplicáveis em outras pesquisas, o que supõe que suas inferências possam ser generalizadas. A análise do PNAFM, mesmo no contexto do federalismo descentralizado brasileiro, evidencia que formulação, implementação e o impacto de uma política pública podem ser afetados pelo seu modelo organizacional e regras de funcionamento. $\mathrm{O}$ argumento central deste trabalho é que estilos de políticas definem tanto possibilidades de adesão, visto o número pequeno de municípios participantes, e alcance de resultados, tal como discutido nas duas variáveis dependentes que foram objeto desta pesquisa.

Regras inseridas em programas federais não apenas organizam sua gestão, mas também incidem na sua efetividade. Nesse sentido, o argumento e o modelo analítico propostos podem servir para o estudo de outras políticas federais, visando a testar sua replicabilidade. Por exemplo, nessa linha, Conlan e Posner (2008) vêm enfatizando o que chamam de "federalismo oportunista" nos Estados Unidos.

Todavia, há limites dessa abordagem, pois seria preciso testar se serve para analisar programas públicos em países não federais ou Estados unitários onde o grau de autonomia dos governos subnacionais frente às esferas centrais é muito menor do que em países federais. Uma segunda questão diz respeito aos processos descentralizadores levado a cabo em vários países, pois só faz sentido projetar capacidades estatais municipais se há perspectiva de fortalecer a gestão desse nível de governo. Uma terceira questão relevante é de ordem operacional, dada a necessidade de existirem bases de dados que permitam análises empíricas longitudinais, sem o que não há como utilizar modelos econométricos como painéis.

Enquanto possibilidades de expandir o modelo teórico e analítico dois caminhos podem ser interessantes: a comparação entre casos de diferentes países e o cotejamento com outros programas com finalidades similares, mas cujos desenhos institucionais são diferentes. No Brasil, por exemplo, o Programa Nacional de Apoio à Modernização da Gestão e do Planejamento dos Estados Brasileiros e do Distrito Federal, implementado desde 2003, baseia-se em um modelo de cooperação federativa menos vertical e hierarquizado (Abrucio, 2007). Esse programa foi concebido e implementado com colaboração intergovernamental para pactuar ações e metas para os governos estaduais que aderiram. Também seria oportuno investigar, de forma comparativa, diferentes arranjos de cooperação federativa e seus resultados para identificar os mecanismos indutores de participação e resultados alcançados, sendo os sistemas nacionais de políticas como o Sistema Único de Saúde (SUS) e o Sistema Único de Assistência Social (SUAS) os casos mais conhecidos.

A pesquisa possui limites para generalizar seus achados, já que a multidimensionalidade do conceito de capacidades estatais não permite afirmar que o programa não gerou impacto algum na modernização da gestão municipal. Ao mesmo tempo, este artigo deixa aberta a possibilidade de novas pesquisas utilizarem outras variáveis que possam testar os argumentos teóricos aqui propostos, bem como avaliar outras ações no âmbito do PNAFM. Outros caminhos de pesquisa podem decorrer da extrapolação para um período maior que considere um número maior de casos envolvendo também a Fase III do programa.

Contudo, considerando as evidências empíricas analisadas, o PNFAM mostrou o verso (o programa com sua concepção e instrumentos de implantação) e o reverso da cooperação federativa (os resultados não alcançados). Com efeito, tomando as duas variáveis de capacidade estatal analisadas, esse modelo de programa e de difusão vertical de políticas não parece ser uma prosa de cooperação federativa alinhada com os desafios de promover a modernização das administrações municipais no Brasil.

\section{REFERÊNCIAS}

Abrucio, F. L. (2007). Trajetória recente da gestão pública brasileira: um balanço crítico e a renovação da agenda de reformas. Revista de Administração Pública. Edição Especial Comemorativa, 1967-2007, 67-86. 
Abrucio, F. L. (2005). A coordenação federativa no Brasil: A experiência do período FHC e os desafios do governo Lula. Revista de Sociologia Politica, 24(1), 41-67.

Afonso, J. R., Araújo, E. A. (2000). A capacidade de gasto dos municípios brasileiros: arrecadação própria e receita disponível. Cadernos de Finannças Públicas, 1(1), 19-30.

Agranoff, R. (2001). Managing within the Matrix: Do Collaborative Intergovernmental Relations Exist? Publius The Journal of Federalism, 31(2), 31-56.

Anderson, W. (1960). Intergovernmental Relations in Review. Minneapolis: University of Minnesota Press.

Arretche, M. T. S. (1999). Políticas sociais no Brasil: Descentralização em um Estado Federativo. Revista Brasileira de Ciências Sociais, 14(40), 111-141.

Andrew, S. A. (2009). Recent Developments in the Study of Interjurisdictional Agreements: An Overview and Assessment. State and Local Government Review 41(2), 133-42.

Angrist, J. D., Pischke, J. (2008). Mostly harmless econometrics: an empiricist's companion. Princeton: Princeton University Press.

Banco Interamericano de Desenvolvimento (1999). Fortalecimento institucional da Gestão Pública. Porto Alegre, RS:Apresentação.

Barbosa, L A., Vaz, J. C. (2019). Arranjos institucionais e capacidades de governo em processos participativos de urbanização: o caso de São Bernardo do Campo-SP. Revista do Serviço Público, 70(1), 35-59.

Bel, G., Mildred, E. W. (2016). Factors Explaining Inter-municipal Cooperation in Service Delivery: A Metaregression Analysis. Journal of Economic Policy Reform 19(2), 91-115.

Bichir, R. et al. (2020). Sistemas Nacionais de Políticas Públicas e seus efeitos na implementação: O caso do Sistema único de Assistência Social (Suas). Revista Brasileira de Ciências Sociais, 35(102), 1-23.

Biesbroek, R., Peter B. G., Tosun, J. (2018). Public Bureaucracy and Climate Change Adaptation. Review of Policy Research, 35(6), 766-791.

Bowman, A. O'M., Kearney, R. C. (1988). Dimensions of State Government Capability. The Western Political Quarterly, 41(2), 341-362.

Burgess, P. M. (1975). Capacity Building and the Elements of Public Management. Public Administration Review, 35(Special Issue), 705-716.

Cardoso. A. L. R, Marenco. A. (2019). Qualidade Burocrática e Performance Estatal: desvendando a caixa preta do município. Administração Pública e Gestão Social, 11(4), 1-21.

Cartilha PNAFM (s/d). Recuperado de https://auadinformatica.files.wordpress.com/2011/04/cartilha-pnafm.pdf.

Cingolani, L. (2013). The State of State Capacity: a review of concepts, evidence and measures. Working Paper Series on Institutions and Economic Growth: IPD WP13. Maastricht: Maastricht Graduate School of Governance. Recuperado de file://Users/eduardo/Downloads/wp2013-053.pdf.

Collins, B. K., Andrew, S. A., Khunwishit, S. (2015). Complex Grant-Contracting and Social Equity: Barriers to Municipal Access in Federal Block Grant Programs. Public Performance \& Management Review, 39(1), 406-429.

Conlan, T. J., Posner, Paul. L. (2008). Intergovernmental management for the twenty-first century. Washington, DC: Brookings Institution Press.

Departamento Nacional de Trânsito. Estatística. Frota. Recuperado em 13 fevereiro, 2016, de <http:// www.denatran.gov.br/frota.htm>.

Elazar, D. J. (1987). Exploring Federalism. Toscallosa: University of Alabama Presss.

Elazar, D. J. (1962). The American Partnership. Chicago: The University of Chicago Press.

Enriquez, E., Centeno, M. A. (2012). State Capacity: Utilization, Durability, and the Role of

Wealth vs. History. International and Multidisciplinary Journal of Social Sciences, 1(2), 130-162.

Evans, P. B. (2003). El hibridismo como estrategia administrativa: combinando la capacidad burocrática con las señales de mercado y la democracia deliberativa. Revista Reforma y Democracia, 25(1), 7-32.

Evans, P. B. (1995). Embedded Autonomy: states and industrial transformation. Princeton, Princeton University Press. 
Eduardo José Grin. O verso e o reverso da cooperação federativa E da difusão vertical de políticas...

Fernandes, F. S. (2016). Capacidade institucional: uma revisão de conceitos e programas federais de governo para o fortalecimento da administração pública. Cadernos EBAPE, 14 (3), 695-704.

Geddes, B. (1994). Politician's Dilemma: building state capacity in Latin America. Los Angeles: University of California Press.

Glenday, G. (1997). Capacity Building in the context of the Kenya Tax Modernization Program. In: M. S. Grindle S. (Ed.). Getting Good Government: capacity building in the public sector of developing countries (pp. 333-368). Cambridge: Harvard University Press.

Grin, E. J., Fernandes, G. (2019). Capacidades Estatales en los Municipios Brasileños: Resultados tímidos en un contexto de autonomía política local y un escenario de dependencia financiera. In: E. J. Grin, E. R. Completa, A. P. Carrera-Hernandéz \& F. L. Abrucio (Eds.). Capacidades Estatales en Gobiernos Locales Iberoamericanos: Actualidad, Brechas Y Perspectivas (pp. 92-148). Rio de Janeiro: FGV.

Grin, E. J., Abrucio, F. Luiz (2019). The co-evolutionary policy style of Brazil: structure and functioning. In: M. Howlett \& J. Tosun (Eds.). Policy Styles and Policy-making: exploring the linkages (pp. 115-136). New York: Routledge.

Grin, E. J., Abrucio, F. L. (2018a). Las capacidades estatales de los municipios brasileños en un contexto de descentralización de políticas. Reforma y Democracia, 70(1), 93-126.

Grin, E. J., Abrucio, F. L. (2018b). Quando nem todas as rotas de cooperação intergovernamental levam ao mesmo caminho: arranjos federativos no Brasil para promover capacidades estatais municipais. Revista do Serviço Público, 69(1), 85-122.

Grin, E. J., Abrucio, F. L. (2017). When feds and locals do not speak the same language: an analysis of dissonances in federative cooperation. Cadernos EBAPE, 14(3), 694-719.

Grin, E. J. (2014). Trajetória e avaliação dos programas federais brasileiros voltados a promover a eficiência administrativa e fiscal dos municípios. Revista de Administração Pública, 48(2), 459-480.

Grindle, M. S. (1996). Challenging the state: Crisis and innovation in Latin America and Africa. Cambridge, USA: Cambridge University Press.

Grodzins, M. (1984). The American System: a new view of government in the United States. Chicago: Rand McNally \& Company.

Howlett, M. (2009). Governance Modes, Policy Regimes and Operational Plans: A Multi-Level Nested Model of Policy Instrument Choice and Policy Design. Policy Sciences 42(1), 73-89.

Howlett, M., Tosun, J. (2019). Policy styles: a new approach. In: M. Howlett \& J. Tosun. (Eds.). Policy Styles and Policy-making: exploring the linkages (pp. 3-22). New York: Routledge.

Instituto Brasileiro de Geografia e Estatística. Produto Interno Bruto dos Municípios. Recuperado em 10 julho, 2015, de <http://www.ibge.gov.br/home/estatistica/pesquisas/pesquisa_resultados.php?id_pesquisa=46>.

Instituto Brasileiro de Geografia e Estatística. Censo Demográfico (ano 2000 e ano 2010). Recuperado em 10 julho, 2015 de <www.ibge.gov.br/home>.

Instituto de Pesquisa Econômica Aplicada. IpeaData. Finanças Públicas. Recuperado em 30 março, 2015, de <http: //www.ipeadata.gov.br/ >.

Kim, J., McDonald, B. Lee, J. (2018). The Nexus of State and Local Capacity in Vertical Policy Diffusion. American Review of Public Administration, 48(2), 188-200.

Kugelmas, E., Sola, L. (1999). Recentralização/Descentralização: Dinâmica do regime federativo no Brasil dos anos 90. Tempo Social. Revista de Sociologia da USP, 11(2), 63-81.

Lae-Cho, C., Wright, D. S. (2001). Managing Carrots and Sticks: Changes in State Administrators' Perceptions of Cooperative and Coercive Federalism during the 1990s Publius - The Journal of Federalism, 31(2), 57-81.

Luna, J. P., Soifer, D. H. (2017). Capturing Subnational Variation in State Capacity: A Survey-Based Approach. American Behavioral Scientist, 61(8), 887-907.

Marenco, A. (2017). Burocracias profissionais ampliam capacidade estatal para implementar políticas? Governos, burocratas e legislação em municípios brasileiros. Dados-Revista de Ciências Sociais, 60(4), 1025-1058 
Marenco, A., Blanco, M. T. S., Joner, W. (2017). Capacidade estatal, burocracia e tributação nos municípios brasileiros. Revista de Sociologia Politica, 25(64), 3-21.

McDonald, B. D., Gabrini, C. J. (2014). Determinants of charter county decisions: An event history analysis of Florida counties. Journal of Public Administration Research and Theory, 24(1), 721-739.

Meza, O. D. et al. (2019). Intermunicipal Cooperation in Metropolitan Regions in Brazil and Mexico: Does Federalism Matter? Urban Affair Review, 55(3), 887-922

Ministério da Fazenda (2011). Programa Nacional de Apoio à Gestão Administrativa e Fiscal dos Municípios Brasileiros. Relatório de Acompanhamento Julho a Dezembro de 2011. Brasília: UCP.

Ministério da Fazenda (2008). Relatório de Gestão 2008. Brasília: Unidade de Coordenação de Programas.

Ministério da Fazenda (2007a). Programa Nacional de Apoio à Gestão Administrativa e Fiscal dos Municípios Brasileiros. Relatório de Acompanhamento Janeiro a Junho de 2007. Brasília: UCP.

Ministério da Fazenda (2007b). Programa Nacional de Apoio à Gestão Administrativa e Fiscal dos Municípios Brasileiros. Relatório de Acompanhamento Julho a Dezembro de 2007. Brasília: UCP.

Ministério da Fazenda (2006). Programa Nacional de Apoio à Gestão Administrativa e Fiscal dos Municípios Brasileiros. Relatório de Acompanhamento Julho a Dezembro de 2006. Brasília: UCP.

Ministério da Fazenda (2005). Relatório Anual de Avaliação. Brasília: MF.

Ministério da Fazenda (2004). Relatório de Gestão 2004. Exercício 2004. Brasília: Unidade de Coordenação de Programas.

Miranda, G. L., Oliveira, V. C. (2018). Capacidade estatal e eficácia na política de atenção a crianças e adolescentes. Revista do Serviço Público, 69(1), 145-178.

Olsen, J. P. (2005). Maybe It Is Time to Rediscover Bureaucracy.Journal of Public Administration Research and Theory, $16(1), 1-24$.

Pereira, J. W. (2018). O Impacto do Programa Nacional de Apoio à Gestão Administrativa e Fiscal dos Municípios Brasileiros (PNAFM) na eficiência fiscal das prefeituras. Caderno de Finanças Públicas, 18(3), 1-68.

Peters, B. G. (2015). Policy capacity in public administration. Policy and Society, 34(1), 219-228.

Pierson, P. (1995). Fragmented Welfare States: Federal Institutions and the Development of Social Policies. Governance: An International Journal of Policy and Administration, 8 (4), 449-478.

Programa das Nações Unidas para o Desenvolvimento (PNUD). Atlas do Desenvolvimento Humano dos Municípios. Recuperado em 07 janeiro, 2016, de <http://www.atlasbrasil.org.br/2013/pt/download/>.

Ramos, M. P., Schabbach, L. M. (2012). O estado da arte da avaliação de políticas públicas: conceituação e exemplos de avaliação no Brasil. Revista de Administração Pública, 46(5), 1271-294.

Reis, A. P. S., Freire, F. S., Wilbert, M. D. (2018). Programa Nacional de Apoio à Gestão Administrativa e Fiscal dos Municípios Brasileiros: Um Estudo de Caso da Relação Entre Custos Versus Benefícios. Revista de Administração, Contabilidade e Economia da FUNDACE, 06(1), 1-19.

Rueschmeyer, D., Evans, P. B. (2002). The state and economic transformation: toward an analysis of the conditions underlying effective intervention. In: P. B. Evans, Dietrich Rueschmeyer \& T. Skocpol (Eds.). Bringing the state back in (pp. 78-106). Cambridge: Cambridge University Press.

Santos, S. R. T., Pimentel, C. (2014). A Adesão ao Programa Nacional de Apoio à Gestão Administrativa e Fiscal nos Municípios Brasileiros e as técnicas gerenciais nos Municípios do Estado do Rio Grande do Sul. Revista de Contabilidade da UFBA, 8(3), 5-20.

Secretaria do Tesouro Nacional. FINBRA - Finanças do Brasil - Dados Contábeis dos Municípios. Recuperado em 03 fevereiro, 2015, de <http://www.tesouro.fazenda.gov.br/pt_PT/contas-anuais>.

Schmitter, P. C., Wageman, C., Obydenkova, A. (2005, outubro). Democratization and State Capacity. Anais do X Congreso Internacional del CLAD sobre la Reforma del Estado y de la Administración Pública, Santiago, Chile, pp. 18-21.

Sikkink, K. (1991). Ideas and institutions: developmentism in Brazil and Argentina. Ithaca and London: Cornell University Press. 
Skocpol, T. (2002). Bringing the state back in: strategies of analisys in current research). In P. B. Evans; D. Rueschmeyer \& T. Skocpol (Eds.). Bringing the state back in (pp. 3-43). Cambridge: Cambridge University Press.

Stead, D. (2018). Policy preferences and the diversity of instrument choice for mitigating climate change impacts in the transport sector. Journal of Environmental Planning and Management, 61(14), 2445-2467.

Vazquez, D. A. (2012, outubro). A influência das capacidades municipais nos resultados das políticas de educação e saúde. Anais do $36^{\circ}$ Encontro Anual da ANPOCS, Caxambu, pp. 21-25.

Veloso, J. F. A. et al. (2011). Gestão municipal no Brasil: um retrato das prefeituras. Brasília, DF: IPEA.

Wolman, H., McManmon, R., Bell, M. E., Brunori, D. (2010). Comparing local government autonomy across states. In: M. E. Bell, D. Brunori, J. Yougman (Eds.), The property tax and local autonomy (pp.69-114). Washington, D.C.: National Tax Association.

Wright, D. S. (1988). Understanding Intergovernmental Relations. Pacific Grove: Brooks/Cole Publishing Company. Wright, D. S., Stenberg, C. W. (2006). Federalism, intergovernmental relations, and intergovernmental management. In: J. Rabin, W. B. Hildret \& G. J. Miller. Handbook of Public Administration. (pp. 407-480). Abingdon: CRC Press.

\section{Notas}

1 Neste artigo, o impacto de uma política é compreendido conforme Ramos e Schabbach (2012, p. 1277): “para captar o impacto recomenda-se combinar ambas as análises (ex ante e ex post) a fim de se comparar o alcance do programa (ex post) com as predições (ex ante)".

2 Os projetos ampliados abrangiam cinco áreas e 24 componentes: modernização administrativa (legislação, ordenamento institucional, recursos humanos, planejamento, gestão urbana e participação social), serviços gerais(atendimento ao cidadão licitações, compras etc.), modernização fiscal (cadastro, arrecadação, cobrança, contencioso administrativo, fiscalização, dívida ativa, dívida pública, estudos econômico-fiscais, orçamento, contabilidade, auditoria e gestão de convênios), tecnologia da informação (gestão, equipamentos, sistemas),coordenação do projeto (manutenção da UEM e gestão do projeto) e administração integrada ao controle espacial (geoprocessamento e dados referenciados). Os projetos simplificados priorizavam: aquisição de Sistemas Aplicativos pré-qualificados pelo BID/MF para gestão municipal tributária, financeira, atendimento e ouvidoria, recursos humanos, compras e patrimônio, protocolo, legislação e informações gerenciais (MF, 2004).3 Informações obtidas com base no Protocolo SIC 16853006290201599, de 10.09.2015 - Min. da Fazenda.

3 Informações obtidas com base no Protocolo SIC 16853006290201599, de 10.09.2015 - Min. da Fazenda. A fase 1 teve início em 18/05/2001e se estendeu 31/12/2012 e as contratações fase 2 iniciaram no ano de 2009, mas foram encerradas em 31/12/2014, conforme Protocolo SIC 16853000909201632, de 16.02.2016. Esta pesquisa considera todos os contratos firmados até $31 / 12 / 2012$, pois não foram recebidas informações de contratos firmados nos anos de 2013 e 2014. Mesmo que houvesse contratos, o ano de 2014 seria desconsiderado para testar o efeito causal do programa e sua implantação, pelo menos, no período de um ano antes da sua entrada no programa. 4 Não se trata de estudo de caso como método, mas sim de uma forma de analisar a cooperação intergovernamental por meio do que Elazar (1962) chama de uma investigação específica de well-screened programs (programas bem selecionados).

5 A pesquisa foi realizada nos anos de 2015 e 2016 e as informações recebidas do Ministério da Fazenda referiam-se às últimas contratações da Fase II realizadas até final do ano de 2012. Por esta razão, a delimitação temporal foi de 2001 a 2012, considerando-se que esse período e o número de municípios da amostra são suficientes para testar empiricamente os argumentos teóricos propostos para avaliar o impacto do programa.

6 Somatório do IPTU, ISS e outros taxas e cobranças municipais (IPEA Data).

7 Valor das operações para manter serviços públicos, manutenção de bens móveis e imóveis, pagamento de pessoal, aquisição de material de consumo, pagamento de serviços e operação de equipamentos públicos (IPEA Data).

8 Na versão simplificada a adesão municipal foi muito reduzida: apenas 23 cidades. 